appearance of the tumour but undetectable clinically. It may be argued that the improved outlook has only been shown in serial studies using historical controls and other factors such as staging and more intensive radiotherapy might be producing these results. But the improvement was so considerable that this is hardly likely. Furthermore, in a study by the Children's Cancer Study Group $\mathrm{A}^{3}$ of 15 children treated by radiotherapy alone eight developed local recurrence or metastases compared with only three out of 17 children concurrently treated by radiotherapy and chemotherapy. This result was significant at the $5 \%$ level.

The ohemotherapy used in this study has not produced any deaths and no undue short- or long-term toxicity. The best regimen, in terms of number of drugs, doses needed, and length of adjuvant therapy, is not yet known. Our regimen is less intense than some reported, yet it appears to give satisfactory results. Co-ordinated studies between centres will be important, especially in view of the implications of these results for the treatment of the commoner adult solid tumours.

We thank Rosemary Finzel for her excellent technical help and Sharon Wilmot for her precise data charting. We are indebted to our colleagues who have kindly referred these children to us.

\section{References}

${ }^{1}$ Pratt, C B, Fournal of Pediatrics, 1969, 74, 791.

2 Donaldson, S S, et al, Cancer, 1973, 31, 26.

${ }^{3}$ Heyn, R M, et al, Cancer, 1974, 34, 2128.

${ }^{4}$ Lederman, M, and Jones, C H, Malignant Diseases in Children, p 151 London, Butterworth, 1974

5 Wilbur, J R, et al, Proceedings of the American Society of Clinical Oncology, $1971,7,56$.

6 Pratt, C B, et al, Cancer Research, 1972, 32, 606.

7 Malpas, J S, et al, in Proceedings of the XI International Cancer Congress, Florence, 1974, p 795.

\title{
Short ACTH test in assessing hypothalamic-pituitary-adrenocortical function
}

\author{
HENRIK KEHLET， MOGENS BLICHERT-TOFT， JÖRGEN LINDHOLM， PETER RASMUSSEN
}

British Medical fournal, 1976, 1, 249-251

\section{Summary}

The adrenocortical response to the simple 30 -minute ACTH stimulation test was compared with the hypothalamic-pituitary-adrenocortical (HPA) response to insulin-induced hypoglycaemia in 25 patients with various degrees of hypothalamic-pituitary malfunction. The correlations between the increase in plasma cortisol during insulin hypoglycaemia and that during ACTH stimulation $(r=0.66)$ and between peak plasma cortisol levels during the two tests $(r=0.90)$ were highly significant. Peak plasma cortisol levels in individual patients were similar on both tests, no patient showing any major discrepancy between the two test results. Thus the simple 30-minute ACTH stimulation test seems to be reliable in detecting imparied HPA function.

\section{Introduction}

Integrated hypothalamic-pituitary-adrenocortical (HPA) function is usually assessed by the insulin-induced hypoglycaemia test, whose clinical value has been clearly shown. ${ }^{12}$ This test, however, is uncomfortable for the patient and requires strict supervision of him throughout the test. Theoretically the simple 30-minute ACTH stimulation test, easy to perform and without discomfort to the patient, tests only adrenocortical function and not the integrated HPA function. We have shown, however, that

\footnotetext{
Department of Neurosurgery, Division of Neuroendocrinology, Rigshospitalet, Copenhagen, Denmark

HENRIK KEHLET, MD, physician (present address: Hvidфre Hospital, 2930 Klampenborg, Denmark)

MOGENS BLICHERT-TOFT, MD, PHD, physician

JÖRGEN LINDHOLM, MD, PHD, physician

PETER RASMUSSEN, MD, PHD, professor
}

the 30-minute ACTH stimulation test reliably predicts the integrated HPA response to surgical stress in patients treated with glucocorticoids. ${ }^{3}$ We therefore compared the adrenocortical response to ACTH with the HPA response to insulininduced hypoglycaemia in patients with various degrees of hypothalamic-pituitary malfunction.

\section{Patients and methods}

Twenty-five patients were investigated (see table). Fourteen (cases 1-14) had undergone hypophysectomy because of pituitary adenoma or cyst, and eight of these patients (cases 1-8) were on glucocorticoid substitution treatment with 25 or $37.5 \mathrm{mg}$ of cortisone acetate daily. Three patients (cases 15-17) had had a pituitary tumour diagnosed but had not yet been subjected to surgery. One patient (case 18) had galactorrhoea but no evidence of hypothalamic-pituitary tumour, and the remaining seven patients (cases 19-25) had various symptoms that made us suspect hypothalamic-pituitary disease. Clinical investigations, however, including neurological and ophthalmological examination, pneumoencephalography, EMI brain-scan, and electroencephalography, showed no evidence of hypothalamic-pituitary disease. Furthermore, secretion of growth hormone (peak plasma value during hypoglycaemia or arginine infusion, or both, $6 \cdot 2-24 \mu \mathrm{g} / \mathrm{l}$ ) and thyroid and gonadal function were normal in these eight patients (cases 18-25) None of the patients had hyperpigmentation or electrolyte disturbances. In the eight patients receiving glucocorticoid substitution treatment the last dose was given the evening before the study. All patients gave their informed consent.

On the day of the examination the patients were fasting, and an insulin hypoglycaemia test was begun between 10 and 11 am by giving crystalline insulin $0 \cdot 15 \mathrm{IU} / \mathrm{kg}$ body weight intravenously. Blood for cortisol and glucose analysis was drawn from an intravenous cannula 10 minutes before and at the insulin injection and 30, 45, 60, 75 , and 90 minutes after the injection. The test was considered adequate only if blood sugar fell to at least $2 \mathrm{mmol} / 1(36 \mathrm{mg} / 100 \mathrm{ml})$ and the patient sweated. In some patients a higher dose of insulin was used to achieve these conditions. On the same day between 3 and 4 pm an ACTH stimulation test was performed by injecting $250 \mu \mathrm{g}$ of $\alpha^{1-24}$ ACTH (tetracosactrin) intravenously. Blood for cortisol determination was drawn immediately before and 30 minutes after ACTH injection.

Blood glucose was measured by a glucose oxidase method and plasma cortisol fluorimetrically as 11-hydroxycorticosteroids. ${ }^{4}$ 
Clinical and experimental data in 25 patients with various degrees of hypothalamic-pituitary malfunction studied with insulin hypoglycaemia test and 30-minute ACTH stimulation test

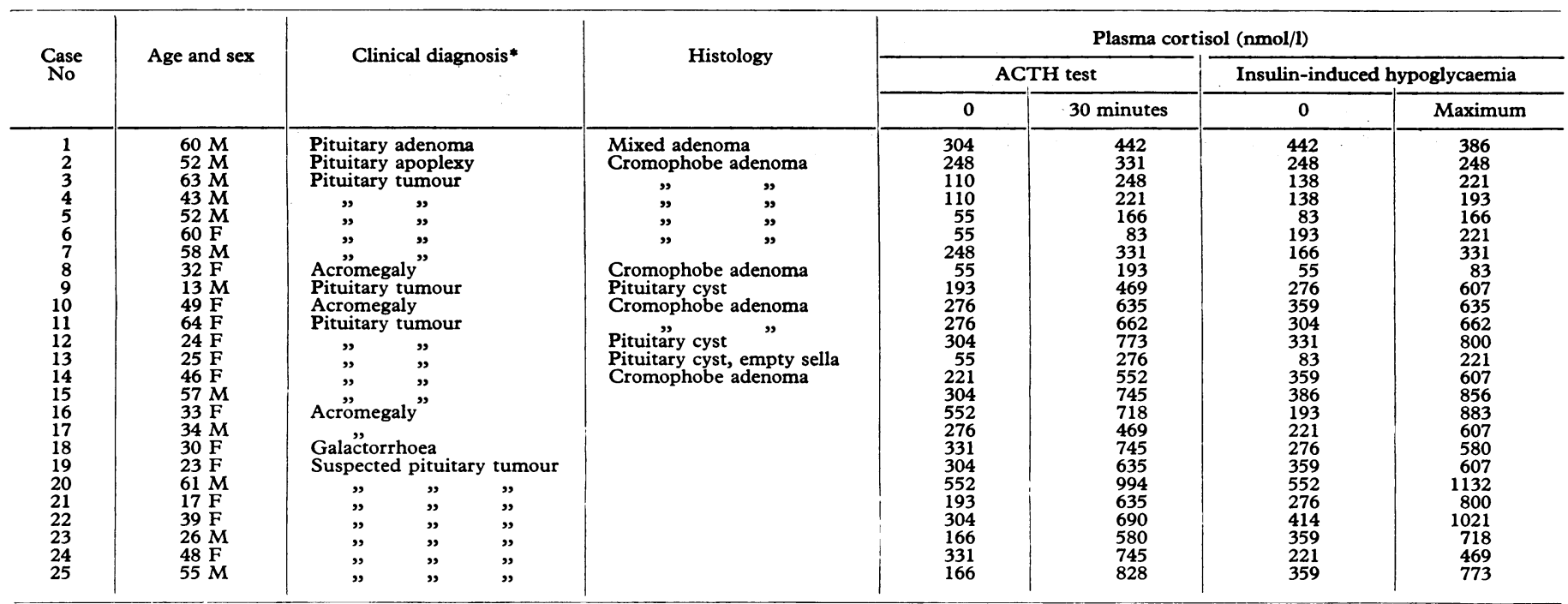

*All tumours, diagnosed or suspected, were non-secreting tumours.

Conversion: SI to traditional units-Cortisol: $1 \mathrm{nmol} / 1 \approx 0.036 \mu \mathrm{g} / 100 \mathrm{ml}$.

\section{Results}

The correlations between the increase in plasma cortisol during insulin-induced hypoglycaemia and that during ACTH stimulation (fig 1) and between the peak plasma cortisol during the insulin hypoglycaemia test and the peak during ACTH stiumlation (fig 2) were highly significant. In individual patients the relation between the outcome of the tests as expressed by the increase in plasma cortisol was poor (fig 1) since basal plasma cortisol levels varied and thereby

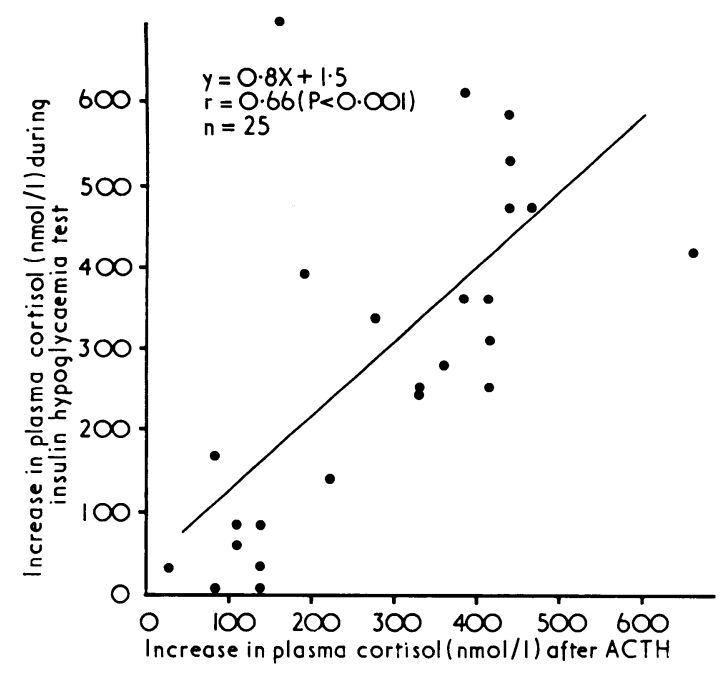

FIG 1 -Comparison between adrenocortical response to $250 \mu \mathrm{g}$ of $\alpha^{1-24}$ ACTH and HPA response to insulin-induced hypoglycaemia (increase in plasma cortisol during two tests) in 25 patients with various degrees of hypothalamic-pituitary malfunction.

Conversion: SI to traditional units-Cortisol: $1 \mathrm{nmol} / 1 \approx 0.036 \mu \mathrm{g} / 100 \mathrm{ml}$.

influenced the test result. On the other hand, the relation between peak plasma cortisol during the two tests was very close in individual patients (fig 2), none showing any major discrepancy between the results. The regression line calculated by correlating the peak plasma cortisol levels during the two tests was not significantly different from the identity line $y=x(P>0 \cdot 1)$. Thus, the two tests apparently gave a uniform expression of the functional capacity of the HPA axis.

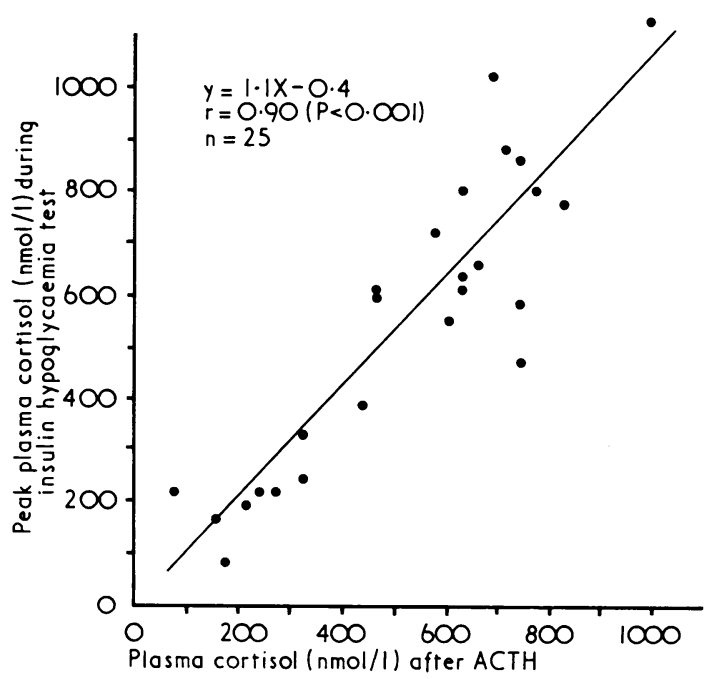

FIG 2-Comparison between adrenocortical response to $250 \mu \mathrm{g}$ of $\alpha^{1-24}$ ACTH and the HPA response to insulin-induced hypoglycaemia (peak plasma cortisol level during the two tests) in 25 patients with various degrees of hypothalamic-pituitary malfunction.

\section{Discussion}

The number of methods for clinically evaluating the integrated function of the various endocrine systems have recently increased considerably owing to the availability of radioimmunological hormone assays and synthetic hypothalamicpituitary releasing hormones. Although a more extensive endocrinological evaluation may be needed to localise the specific lesion in a patient with a proved dysfunction, simple inexpensive screening tests are still desirable. It has recently been reported that the pituitary secretion of five anterior pituitary hormones can be comprehensively classified within a few hours in wellequipped endocrinological centres. ${ }^{5}$ The integrated function of the HPA axis may be evaluated by the metyrapone test; the pyrogen test; the lysine-vasopressin test; or the insulin hypoglycaemia test-of which the last is probably the most valuable. ${ }^{6}$ The short ACTH stimulation test, which theoretically tests only the adrenocortical function, has been accepted as a test for 
primary adrenocortical insufficiency ${ }^{2} 8$ but not for secondary adrenocortical insufficiency because of the possibility of a preserved normal adrenocortical function in secondary insufficiency. Nevertheless, we have recently shown in glucocorticoid-treated patients the value of the simple ACTH stimulation test in assessing the integrated HPA function in secondary insufficiency. ${ }^{3}$

We compared the result of the simple ACTH stimulation test with the HPA response to insulin hypoglycaemia in patients with or without hypothalamic-pituitary disease and varying degrees of adrenocortical insufficiency. A very close correlation was found between the peak plasma cortisol after ACTH and after insulin hypoglycaemia in each patient. It should be emphasised that a patient with borderline results on one test will also have borderline results on the other test, indicating that a borderline ACTH test result should be followed by further evaluation of the HPA function. Our results suggest that a definitely normal response to ACTH is most unlikely to coexist with an impaired response to insulin hypoglycaemia. Examples of such a discrepancy have been reported, ${ }^{2}{ }^{9}$ but information on whether both sweating and low blood glucose values were obtained during insulin hypoglycaemia was not given.

In conclusion, our results suggest that the simple 30-minute ACTH stimulation test is a reliable screening test for impaired HPA function.

\section{References}

1 Jacobs, H S, and Nabarro, J D N, Quarterly fournal of Medicine, 1969, 38, 475.

2 Landon, J, et al, Fournal of Clinical Investigation, 1966, 45, 437

${ }^{3}$ Kehlet, H, and Binder, C, British Medical fournal, 1973, 2, 147.

4 Nielsen, E, and Asfeldt, V H, Scandinavian fournal of Clinical and Laboratory Investigation, 1967, 20, 185.

5 Mortimer, C H, et al, Clinical Endocrinology, 1973, 2, 317.

${ }^{6}$ British Medical fournal, 1970, 1, 644.

7 Speckart, F, Nicoloff, J T, and Bethune, J E, Archives of Internal Medicine, $1971,128,761$

8 Irvine, W J, and Barnes, E W, in Clinics in Endocrinology and Metabolism, ed A S Mason, vol 1, p 549. Philadelphia, 1972

${ }^{9}$ Asfeldt, V H, Acta Medica Scandinavica, 1972, 191, 369.

\title{
Renin concentrations and effects of propranolol and spironolactone in patients with hypertension
}

\author{
BENGT E KARLBERG， BERTIL KÅGEDAL， LENNART TEGLER， KERSTIN TOLAGEN
}

British Medical fournal, 1976, 1, 251-254

\section{Summary}

In a crossover study 32 patients with hypertension were randomly allocated to treatment with spironolactone $200 \mathrm{mg} /$ day for two months, propranolol $320 \mathrm{mg} /$ day for two months, and a combination of both drugs at half the dose. Between the treatments placebo was given for two months. Both spironolactone and propranolol lowered the blood pressure significantly in both positions.

The initial plasma renin activity (PRA) levels ranged from 0.4 to $5.0 \mu \mathrm{g}$ angiotensin $\mathrm{I}^{-1} \mathrm{~h}^{-1}$, and there was a close correlation between these levels and the effects of the drugs: with increasing PRA the response to propranolol was better while the opposite was true for spironolactone. Spironolactone reduced the blood pressure more at eight than at four weeks, while no such difference could be shown for propranolol. Spironolactone and propranolol together decreased the blood pressure still further irrespective of the initial PRA. All patients achieved a normal supine blood pressure.

\footnotetext{
Department of Internal Medicine, University Hospital, S-581 85 Linköping, Sweden

BENGT E KARLBERG, MD, associate professor, endocrine unit

LENNART TEGLER, MD, senior staff physician

KERSTIN TOLAGEN, MD, senior staff physician

Department of Clinical Chemistry, University Hospital, S-581 85 Linkoping, Sweden

BERTIL KÅGEDAL, MD, senior lecturer
}

These results support the concept that the reninangiotensin-aldosterone system may be involved in primary hypertension.

\section{Introduction}

Recently much interest has been focused on the reninangiotensin-aldosterone system and its role in primary (essential) hypertension. ${ }^{1}$ It has been proposed that plasma renin activity (PRA) might have both prognostic ${ }^{2}$ and therapeutic implications. ${ }^{3}$ Bühler et $a l^{3}$ showed that hypertensive patients with normal or high PRA responded more favourably to treatment with beta-adrenergic-blocking drugs, but others-for example, Morgan et $a l^{4}$-could not confirm this. Many studies have verified that low renin hypertension responds best to volumedepleting drugs, such as diuretics or aldosterone antagonists. ${ }^{5-7}$

Our aim was to see whether the response to propranolol or spironolactone was related to the initial PRA. We also wanted to compare the efficacy of propranolol, spironolactone, and the combination of the two drugs in the treatment of primary hypertension.

\section{Patients and methods}

Thirty-two consecutive outpatients with hypertension, 14 men and 18 women ranging in age from 27 to 62 years (mean 46), entered the 10 -month trial. The average known duration of hypertension was 3.4 years (range $0-20$ ); 23 patients had grade I hypertension (World Health Organisation classification) and nine had grade II hypertension. None had eye-ground changes worse than grade II. Nineteen patients had never received antihypertensive treatment, and in the remaining 13 all medication had been withdrawn for at least four weeks. No patients with obstructive lung disease, diabetes mellitus, or hepatic or renal disorder were admitted. None had malignant or secondary 